\title{
Factors affecting successful endoscopic sclerotherapy for oesophageal varices
}

\author{
J D R ROSE, M D CRANE, AND P M SMITH
}

From the Departments of Gastroenterology and Radiology, Llandough Hospital, Penarth, South Glamorgan

SUMMARY Forty patients with bleeding oesophageal varices were studied during treatment by endoscopic sclerotherapy to discover what factors determine successful outcome. Large varices required more injections than small varices for obliteration, and rebleeding during treatment occurred only in patients with large varices. Radiological studies with sclerosant contrast mixture showed that in two groups of varices of comparable size, intravenous sclerosant was significantly more effective, leading to thrombosis in $8 / 10$ as opposed to only $3 / 10$ after paravasal injection $(\mathrm{p}<0.05)$. Intravenous contrast was rapidly cleared upwards, whereas paravasal contrast formed a rounded opacity alongside the vein that persisted for approximately 90 minutes, responsible for the complications of oesophageal ulceration and stenosis.

Oesophageal sclerotherapy is now accepted as a successful treatment for bleeding varices. ${ }^{1}$ The relative efficacy and safety of sclerosant injected intravenously or paravenously, however, has not been established and nor is it known why the number of treatments required for variceal obliteration varies from patient to patient. We have examined these factors and report our results here.

\section{Methods}

\section{PATIENTS}

Forty patients, aged 17-77 years, have been treated by injection sclerotherapy after a bleed from oesophageal varices. Twenty three were men and 17 women. Cirrhosis was present in 34; 17 alcoholic, eight primary biliary cirrhosis, six cryptogenic, two chronic active hepatitis, and one secondary biliary. The remainder had presinusoidal portal hypertension. All alcoholics abstained during the period of the study. The severity of their liver disease was graded according to a modification of Child's classification at the time of admission. ${ }^{2}$ Successful treatment was regarded as variceal obliteration without recourse to surgery.

Acutely bleeding patients were treated by transfusion and Sengstaken tube tamponade, with sclerotherapy the next day once bleeding had been

Address for correspondence: Dr J D R Rose. Llandough Hospital, Penarth, South Glamorgan CF6 1 XX.

Received for publication 14 January 1983 controlled. Under diazepam sedation an endviewing fibrescope was passed and $2-3 \mathrm{ml}$ of $3 \%$ sodium tetradecyl sulphate was injected into each varix just above the gastro-oesophageal junction. Oesophageal relaxation was achieved by $40 \mathrm{mg}$ hyoscine butylbromide (Buscopan) intravenously. No outer sheath was used. ${ }^{3}$ Variceal position was recorded on a clockface system, and the size of each variceal column was assessed by a subjective grading from 1 to 4 , corresponding with that recently described by Paquet. The sums of the variceal grades $1 \mathrm{~cm}$ and $5 \mathrm{~cm}$ above the gastro-oesophageal junction constituted a variceal score. Adequate grading was not possible in five patients and two had been injected once in another hospital.

Injections were generally performed at weekly intervals until the varices were thrombosed or markedly reduced in size. Thereafter treatment took place monthly until varices had disappeared.

Eight of the $\mathbf{4 0}$ patients took part in a radiologically controlled study to determine the effect of the site of injection. Two millilitres of a 1:3 mixture of $76 \%$ Urografin and $3 \%$ sodium tetradecyl sulphate were injected either intravenously or paravenously under radiological screening into two groups of 10 varices which were matched for size. Size and thrombosis of varices were assessed four weeks later without intervening injection. Thrombosis was determined by inspection of the varix for emptying and filling on respiration and straining, and by lateral pressure on the varix with the needle sheath. A patent varix will indent and the sheath can be 
drawn smoothly across, but a thrombosed varix offers resistance, will not indent and the flexible needle sheath itself bends.

Using the same radiological technique further studies were performed to assess how frequently an intended intravariceal injection was in fact paravariceal.

\section{Results}

Sclerotherapy alone was successful in 30 patients. Two further patients bled severely early in treatment and required oesophageal transection with a stapling gun ${ }^{5}$ before successful variceal elimination. The remaining eight patients died before therapy could be completed, five from hepatic failure, two from hepatic malignancy, and only one from bleeding varices. Further uncontrollable bleeding necessitated oesophageal transection in two of these before death. Minor bleeding occurred during treatment in a further 16 patients. This rebleeding occurred early in treatment in all but two patients, while the varices were still large (Grade 3 or 4). There was no relationship between Child's grade and the initial variceal score nor with the success of treatment, although the incidence of rebleeding was higher in Child's grade $C$ (Table).

Patients with multiple large varices (Grades 3-4) required more injections to achieve obliteration than those with small varices (Grades 1 and 2) (Fig. $1)$, the number of injections correlating with the variceal score $(r=0.587, p<0.001)$. No patient with small varices only bled from them during treatment, except for one with a sclerosant related ulcer. In comparison, 10 out of 13 patients who had three or more large varices rebled. The difference between the numbers of large varices in the rebleeding and non-rebleeding groups is significant $(p<0.01$ MannWhitney U Test) (Fig. 2).

\section{RADIOLOGICAL STUDIES}

When contrast was injected with the sclerosant into a varix it was rapidly cleared upwards in the direction of blood flow. Of 59 intended intravariceal injections whose site could be accurately identified

Table Relationship of child's grade to rebleeding during sclerotherapy

\begin{tabular}{lrll}
\hline & $A$ & $B$ & $C$ \\
\hline No rebleed & 12 & 5 & 1 \\
Rebleed* & 8 & 5 & 8 \\
\hline
\end{tabular}

* One patient who bled from an oesophageal ulcer excluded. More grade $\mathrm{C}$ patients in rebleeding group compared to $\mathrm{A}+\mathrm{B}$. $\mathrm{p}=0 \cdot 017$. Exact test.

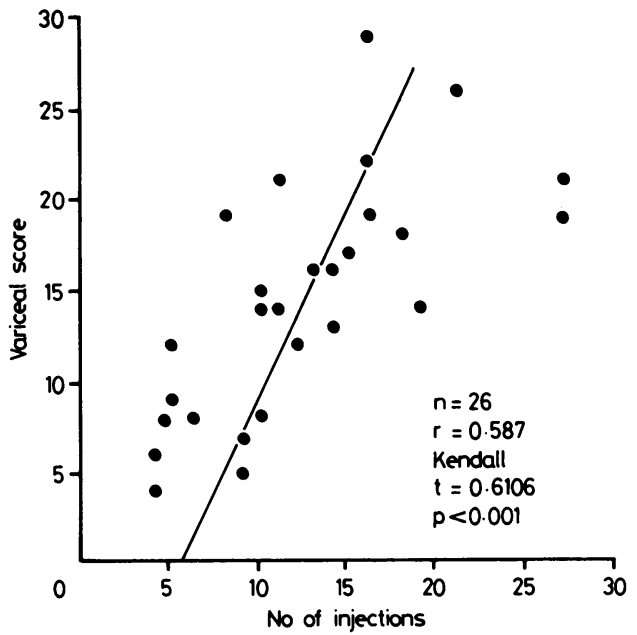

Fig. 1 Correlation between initial variceal score and number of injections required to obliterate varices.

radiologically, 15 were paravasal $(25 \%)$. Large varices were successfully entered in $82 \%(31 / 38)$ of injections compared with $62 \%(13 / 21)$ for small varices. Paravasal injection of contrast led to the formation of a rounded opacity alongside the vein which elongated slowly. This was visible on screening for up to 90 minutes.

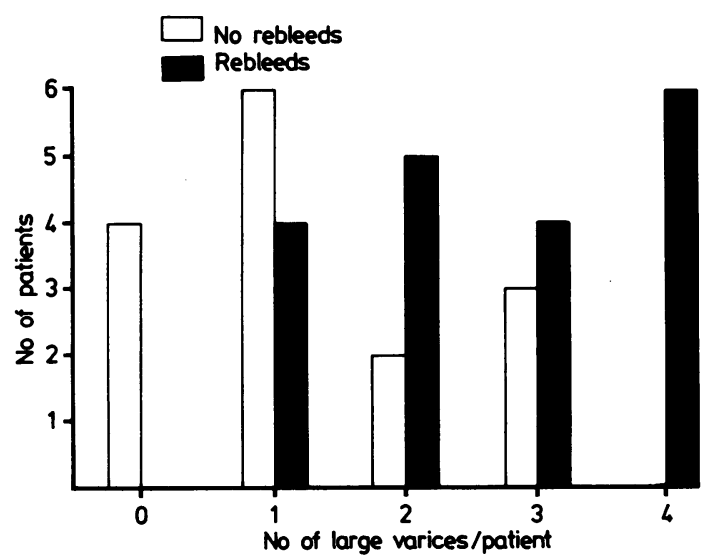

Fig. 2 Relationship of numbers of large varices present initially to rebleeding.

Excluded from fig: four not properly assessed initially, one patient who bled from oesophageal ulcer and one patient who died immediately from hepatic failure.

Difference in number of large varices between rebleeding and non-rebleeding group is significant $p<0.01$ MannWhitney $U$ Test. 
Twenty varices were injected once with the sclerosant-contrast mixture, 10 intravenously and 10 paravenously (Fig. 3). Intravariceal injection thrombosed eight out of 10 varices and gave rise to no complications; paravasal injection did not reduce variceal size, thrombosed only three out of 10 varices and was significantly less successful $(p<0.05)$. One iatrogenic ulcer, which bled, was produced by paravasal injection and another patient complained of dysphagia for some weeks.

\section{Discussion}

Variceal size, and not portal pressure, determines the risk of bleeding ${ }^{6}$ and patients of Child's grade $C$ rebleed more frequently. ${ }^{1}$ This study confirms also that patients with poor liver function have an increased chance of rebleeding during sclerotherapy and that the number of large varices also increases the risk of rebleeding, but neither factor alters the success of the treatment.

The assessment of both variceal size and thrombosis in this study was subjective but grading of size compares well with that of Paquet ${ }^{4}$ and a recent visit by one of us has confirmed this comparability.

Large varices required more injections than small
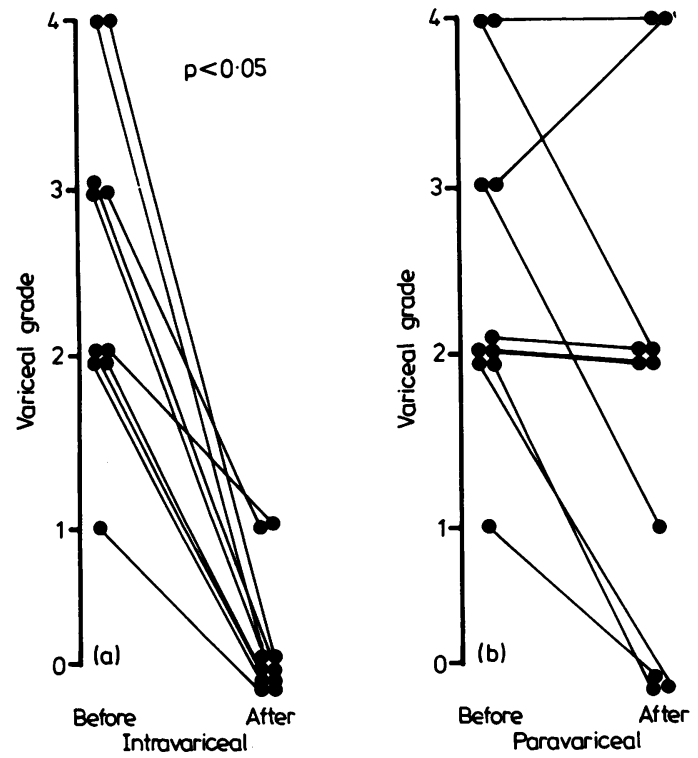

Fig. 3 Results of intravariceal and paravariceal injection. Grade 0 is no varix visible or varix thrombosed. Thrombosis in intravariceal group significantly higher $p=0.032$ exact test. ones for obliteration, and proven intravariceal injection was very effective even when the varix was large. Our studies suggest that one in five injections into a large varix is paravasal and one in three for small varices. As it is impossible to aspirate blood up the injection needle into the syringe at the time of treatment, the endoscopist cannot check that the needle is in the vein, so the chance of extravascular injection of sclerosant increases as the vein becomes smaller. A proportion of injections are, therefore, less effective because the sclerosant is not intravenous, although paravasal injection may thrombose some small varices. The relationship between variceal obliteration and the development of an oesophageal stricture is probably a feature of multiple injections, some of which extravasate and produce submucosal fibrosis. ${ }^{7}$ Barsoum et $a l^{8}$ found submucosal extravasation during intravariceal injection in three out of six patients in the only other radiologically controlled study published. They used a rigid endoscope, with a rigid needle and injected $10 \mathrm{ml}$ of sclerosant per varix, however, which may account for the high incidence of extravasation.

In previously reported series ${ }^{19} 27 \%$ of patients developed oesophageal ulcers, and the pattern of paravasal injection suggests that this results from sclerosant spreading along the vein sheath, ulcerating the overlying mucosa. Occasionally the ulceration may even penetrate the vein wall to produce haemorrhage.

Injection of sclerosant in volumes and concentrations also used for intravariceal injection appears both ineffective and potentially dangerous. This is to be distinguished from 'Ösophaguswandsklerosierung' - oesophageal wall sclerosis - pioneered by Wodak ${ }^{10}$ and practised by Paquet. ${ }^{11}$ Sclerosis in this technique is achieved by multiple (30-40) submucosal injections of dilute sclerosant to produce a protective fibrous sheath.

Although intravariceal injection is followed by only a transient exposure of the endothelium to sclerosant, it is, nevertheless, effective. Animal work suggests that one second suffices to produce irreversible maceration ${ }^{12}$ and thrombosis. ${ }^{13}$ Because the sclerosants used are detergents they act as wetting agents and have surfactant properties even when considerably diluted. ${ }^{14}$

Sclerotherapy is usually effective and safe but injection should be intravariceal for maximum effect and to avoid ulcer or stricture formation. While poor liver function and multiple large varices increase the risk of rebleeding, there is no subgroup of patients for whom sclerotherapy is inappropriate and we have successfully treated two of the three patients who had three or more large varices and were in Child's grade C. 


\section{References}

1 MacDougall BRD, Westaby D, Theodossi A, Dawson $\mathrm{JL}$, Williams $\mathrm{R}$. Increased long-term survival in variceal haemorrhage using injection sclerotherapy. Lancet 1982; 1: 124-7.

2 Pugh RNH, Murray-Lyon IM, Dawson JL, Pietroni MC, Williams R. Transection of the oesophagus for bleeding oesophageal varices. Br J Surg 1973; 60: 646-9.

3 Williams KGD, Dawson JL. Fibreoptic injection of oesophageal varices. Br Med J 1979; 2: 766-77.

4 Paquet K-J. Prophylactic endoscopic sclerosing treatment of the esophageal wall in varices - A prospective controlled randomized trial. Endoscopy 1982; 14: 4-5.

5 Johnston GW. Treatment of bleeding varices by oesophageal transection with the SPTU gun. Ann $R$ Coll Surg Engl 1977; 59: 404-8.

6 Lebrec D, De Fleury P, Rueff B, Bahum H, Benhamou JP. Portal hypertension, size of esophageal varices and risk of gastrointestinal bleeding in alcoholic cirrhosis. Gastroenterology 1980; 79: 1139-44.
7 Evans DMD, Jones DB, Cleary BK, Smith PM. Oesophageal varices treated by sclerotherapy: a histopathological study. Gut 1982; 23: 615-20.

8 Barsoum MS, Khattar NY, Risk-Allah MA. Technical aspects of injection sclerotherapy of acute oesophageal variceal haemorrhage as seen by radiography. BrJ Surg 1978; 65: 588-9.

9 Smith PM, Jones DB, Rose JDR. Simplified fibre endoscopic sclerotherapy for oesophageal varices. $J R$ Coll Physicians Lond 1982; 16: 236-8.

10 Wodak E. Osophagusvarizen - Blutung bei portaler Hypertension; ihre Therapie und Prophylaxe. Wien med Wochenschr 1960; 110: 581-3.

11 Raschke E, Paquet KJ. Management of hemorrhage from esophageal varices using esophagoscopic sclerosing method. Ann Surg 1973; 177: 99-102.

12 Dietrich HP, Sinapius D. Experimentelle Endothelschädigung durch Varizenverödungsmittel. Arzneim Forsch 1968; 18: 116-20.

13 Blenkinsopp WK. Effect of injected sclerosant (Tetradecyl Sulphate of Sodium) on rat veins. Angiologica 1968; 5: 386-96.

14 Imhoff E, Stemmer R. Classification et mécanisme d'action des sclérosants. Phlebologie 1969; 22: 143-8. 